\title{
Detection of Ureaplasma DNA in Endotracheal Samples Is Associated With Bronchopulmonary Dysplasia After Adjustment for Multiple Risk Factors
}

\author{
TARAH T. COLAIZY, CYNTHIA D. MORRIS, JODI LAPIDUS, RONALD S. SKLAR, AND DE-ANN M. PILLERS
}

Department of Pediatrics [T.T.C.], University of Iowa, Carver College of Medicine, Iowa City, Iowa 52241; Departments of Medical Informatics [C.D.M.], Public Health and Preventative Medicine [J.L.], and Pediatrics [D.-A. M.P.], OR Health and Science University, Portland, Oregon 97239; Neonatology [R.S.S.], Kaiser Permanente Northwest, Portland, Oregon 97232

\begin{abstract}
Microorganisms are hypothesized to contribute to the pathogenesis of bronchopulmonary dysplasia (BPD) in very low birth weight (VLBW) infants. This hypothesis remains controversial. We sought to determine whether endotracheal colonization with Ureaplasma sp., adenovirus, or Chlamydia sp. increases the risk of BPD. Intubated VLBW infants were included. Polymerase chain reaction (PCR) analysis was used to detect Ureaplasma sp., adenovirus, and Chlamydia sp. The outcome measure was BPD or death due to lung disease. Detection of microorganisms was compared between subjects with and without BPD. Logistic regression was used to control for covariates. Of 139 subjects, 33 (25\%) screened positive for Ureaplasma sp., 22 of 136 (16\%) were positive for adenovirus; eight of $133(6 \%)$ were positive for Chlamydia sp. At 36 wk postmenstrual age, 14 patients had died, $68(57 \%)$ had BPD. Detection of Ureaplasma sp. was associated with BPD or death $(p<0.001)$; adenovirus $(p=0.52)$ and Chlamydia sp. $(p=0.33)$ were not. Controlling confounding factors, the odds ratio for Ureaplasma sp. and BPD or death was $4.2(95 \%$ CI 1.03, 17). In our population, detection of Ureaplasma sp., but not adenovirus or Chlamydia sp. was associated with BPD or death due to lung disease. (Pediatr Res 61: 578-583, 2007)
\end{abstract}

$\mathrm{B}^{\mathrm{P}}$ PD represents an ongoing challenge in neonatal care. BPD is a mixed obstructive/restrictive lung disease of preterm infants, with very low birth weight infants (VLBW, $<1500 \mathrm{~g}$ ) being at highest risk of significant morbidity and mortality $(1,2)$. BPD has been attributed to the effects of treatment of infant respiratory distress syndrome (iRDS), particularly oxygen supplementation and mechanical ventilation (3). Despite routine use of surfactant, gentle ventilation techniques, and judicious use of oxygen therapy, BPD remains a major morbidity for VLBW infants. Infants with minimal exposure to mechanical ventilation are also affected by BPD, suggesting that other factors are involved in its pathogenesis $(4,5)$.

Received July 6, 2006; accepted December 6, 2006.

Correspondence: De-Ann M. Pillers, M.D., Ph.D., Department of Pediatrics, NRC-5, OR Health \& Science University, 3181 SW Sam Jackson Park Road, Portland, OR 97239; e-mail: pillersd@ohsu.edu

This work was funded by NIH NRSA F32 (F32 HD0-44332) (T.T.C.), Northwest Health Foundation (D.M.P.), American Lung Association of Oregon (R.S.) and by a generous gift to the Doernbecher Children's Hospital Foundation in memory of a son, who died too young.

DOI: $10.1203 / p d r .0 b 013 e 318045 b e 03$
The development of lung inflammation resulting in abnormal alveolar development may be a common pathway that links these risk factors (2). Infectious microorganisms in the pulmonary tree may contribute to such inflammation. Ureaplasma sp. are associated with both a pulmonary and a systemic inflammatory response (6-13). Pulmonary adenovirus has been linked with BPD, although no studies have investigated the inflammatory response in newborn infants (14). Chlamydia sp. have been serologically linked to BPD (15). However, studies performed during routine maternal screening yielded low numbers of colonized infants, and no association with BPD was demonstrated $(16,17)$.

Maternal Ureaplasma sp. infection is associated with chorioamnionitis, an inflammatory disorder of the membranes that can contribute to premature birth (18). The risk of vertical transmission of the organism is inversely proportional to gestational age, as is the risk of BPD (19). Associations between neonatal pulmonary colonization with Ureaplasma sp. and development of BPD have been shown (16,20-28), but the association remains controversial (17,29-35). Study design limitations that could minimize the likelihood of detecting an association include small sample size, failure to consider estimated gestational age (EGA) or birth weight during statistical analysis, failure to account for other pathogens, and varying definitions of BPD.

We used PCR to detect Ureaplasma sp. PCR has a lower false-negative rate than clinical culture and can detect organisms when simultaneous cultures fail to do so $(13,36,37)$, making it an ideal assay for fastidious organisms that are difficult to culture under routine clinical laboratory conditions.

We undertook a prospective cohort study of VLBW infants, screening them for the presence of Ureaplasma sp., adenovirus, and Chlamydia sp. in the lungs using PCR on endotracheal aspirates and following them for the development of BPD. We identified potential confounding variables and adjusted for them in our analysis. Our goal was to determine the contribution of pulmonary detection of these microorganisms to the development of BPD.

Abbreviations: BPD, bronchopulmonary dysplasia; EGA, estimated gestational age; PMA, postmenstrual age; VLBW, very low birth weight 


\section{METHODS}

Study design, inclusion/exclusion criteria. We designed a prospective cohort study of the contribution of endotracheal detection of infectious microorganisms to the development of BPD in VLBW infants. The Institutional Review Board of Oregon Health and Science University (OHSU) approved the protocol and granted a waiver of patient consent, as the study samples were deemed medical waste. Samples were coded to preserve anonymity during analysis.

All VLBW infants admitted to OHSU Hospital before $72 \mathrm{~h}$ of age who required intubation and mechanical ventilation were eligible for study entry. Patients were excluded if they had congenital anomalies, congenital heart disease, or chromosomal anomalies. Endotracheal aspirates were obtained within the first $72 \mathrm{~h}$ of life. Specimens were screened for Ureaplasma sp., adenovirus, and Chlamydia sp. by PCR. Clinical data regarding known risk factors for chronic lung disease were collected.

Outcome definitions. We used a common definition of BPD: need for supplemental oxygen at $36 \mathrm{wk}$ postmenstrual age (PMA) (1). Infants met this criteria if they had a room air $\mathrm{SpO}_{2}$ of $<88 \%$ by bedside pulse oximetry (Spacelabs Medical, Issaquah, WA).

A combined outcome of death due to lung disease or BPD at 36 wk PMA was also modeled. For infants who died before 36 wk PMA, whose death was due to respiratory failure, pneumothorax, pulmonary hemorrhage, iRDS, or pulmonary hypertension, were included in the death-due-to-lung-disease group. These patients were added to the survivors with BPD at 36 wk PMA to form the combined outcome group.

Clinical data collection. Respiratory course, comorbid conditions, and preexisting demographic risks for BPD were considered as potential confounding variables. Total white blood cell counts were collected at birth as a measure of systemic inflammation. Clinical data were abstracted from hospital charts after hospital discharge.

To keep study personnel blinded, samples were coded anonymously. Clinical data collection was completed before PCR results were decoded to prevent bias.

Sample collection. Endotracheal aspirates were obtained using in-line suction sets and sterile suction traps (Busse Hospital Disposable, Hauppauge, $\mathrm{NY}$ ) as part of routine clinical care. Up to $1 \mathrm{~mL}$ of sterile nonbacteriostatic saline was instilled into the trachea, with a resultant 0.5 to $1.0 \mathrm{~mL}$ sample obtained. Samples were stored at $-80^{\circ} \mathrm{C}$.

Sample preparation. Three hundred microliters of aspirate was centrifuged at $14,000 \times g$ for $20 \mathrm{~min}$. The pellet was incubated at $60^{\circ} \mathrm{C}$ for $60 \mathrm{~min}$ with $50 \mu \mathrm{L}$ of solution A $(10 \mathrm{mM}$ Tris $\mathrm{HCl}, \mathrm{pH} 8.3,100 \mathrm{mM} \mathrm{KCl}, 2.5 \mathrm{mM}$ $\mathrm{MgCl}_{2}$ ) and $100 \mu \mathrm{L}$ of solution B (1\% Tween $20,10 \mathrm{mM}$ Tris $\mathrm{HCl}, 1 \%$ Triton $\mathrm{X}, 2.5 \mathrm{mM} \mathrm{MgCl}, 120 \mu \mathrm{g} / \mathrm{mL}$ proteinase $\mathrm{K}$ ). It was heated at $95^{\circ} \mathrm{C}$ for $10 \mathrm{~min}$ to inactivate the proteinase $\mathrm{K}$, quenched on ice, and stored at $-20^{\circ} \mathrm{C}$ until PCR analysis.

Primers. Primers used for detection of Ureaplasma sp., Chlamydia sp., and adenovirus were synthesized and purified by Invitrogen (Carslbad, CA), and are shown in Table 1.

PCR screening for microorganisms. Primers designed and validated in neonatal endotracheal aspirate samples by Blanchard and colleagues (38) were used to amplify a 429-bp fragment of the urease gene common to all serotypes of Ureaplasma sp. The Ampliwax (Perkin-Elmer ABI)-mediated hot-start PCR technique was performed in a $50-\mu \mathrm{L}$ reaction mix. The lower suspension contained $2.5 \mu \mathrm{L}$ of each primer (U4 and $\mathrm{U} 5,10 \mu \mathrm{mol}$ ), $1 \mu \mathrm{L}$ deoxyribonucleoside triphosphate and distilled and deionized $\mathrm{H}_{2} \mathrm{O}(\mathrm{ddH} 2 \mathrm{O})$ to $20-\mu \mathrm{L}$ volume and was sealed with a $50-\mu \mathrm{L}$ Ampliwax gem melted at $72^{\circ} \mathrm{C}$. The upper suspension contained $10 \times$ PCR buffer $(5 \mu \mathrm{L}), 25 \mathrm{mM}$ $\mathrm{MgCl}_{2}(6 \mu \mathrm{L}), 1 \mathrm{U}$ Taq polymerase, and ddH20 to $25-\mu \mathrm{L}$ volume. Last, and in a different location from where the PCR reaction mixes were assembled (to minimize potential contamination of reagents by PCR products), $5 \mu \mathrm{L}$ of experimental sample was added. Positive and negative controls were used. A GenAmp 2400 DNA thermal cycler (Perkin-Elmer-Cetus) was used for 40 cycles of $20 \mathrm{~s}$ at $95^{\circ} \mathrm{C}$ for denaturation, $60 \mathrm{~s}$ at $62^{\circ} \mathrm{C}$ for primer annealing, and $30 \mathrm{~s}$ at $72^{\circ} \mathrm{C}$ for extension.

Chlamydia sp. and adenovirus are also amenable to PCR detection (14). The Ampliwax hot-start PCR technique described above was used, substituting appropriate primers, and adjusting PCR protocols as noted below.

A 330-bp fragment of the hexon gene of adenovirus was amplified using nested PCR with ADH-01 and ADH-02 primers (14). These primers detect at least 10 subtypes of adenovirus, including $1,2,3,5,6,7,18,31,41$, and 50 . The protocol for the primary reaction was $5 \mathrm{~min}$ of incubation at $94^{\circ} \mathrm{C}$, followed by 40 cycles of $45 \mathrm{~s}$ at $94^{\circ} \mathrm{C}, 45 \mathrm{~s}$ at $64^{\circ} \mathrm{C}$, and $45^{\circ} \mathrm{s}$ at $72^{\circ} \mathrm{C}$. Two microliters of the primary PCR product was used in the secondary PCR reaction, with the $\mathrm{ADH}-11$ and $\mathrm{ADH}-22$ primers.

A 609-bp fragment of Chlamydia (trachomatis, psittaci, pneumoniae) (16S rRNA gene) was amplified with a single PCR reaction: 5-min incubation at $94^{\circ} \mathrm{C}$, followed by 40 cycles of $45 \mathrm{~s}$ at $94^{\circ} \mathrm{C}, 45 \mathrm{~s}$ at $64 \mathrm{C}, 45 \mathrm{~s}$ at $72^{\circ} \mathrm{C}$.

Positive and negative controls. Positive controls consisted of stock isolates of Ureaplasma sp. obtained from ATCC (Manassas, VA), and samples of Chlamydia trachomatis and adenovirus obtained from the OHSU Department of Microbiology. Negative controls consisted of pH 7.5 TE buffer. Samples were tested at least twice to ensure reliable results.

Analysis of PCR products. Amplified products were analyzed by electrophoresis through a $2 \%$ SeaKem LE agarose gel (Cambrex) at $60 \mathrm{~V}$ for $3 \mathrm{~h}$, stained with $0.5 \mu \mathrm{g} / \mathrm{mL}$ ethidium bromide (Sigma Chemical Co., St. Louis, $\mathrm{MO})$, and visualized with ultraviolet light.

Data analysis. Univariate analyses, including $\chi^{2}$, Fisher's exact test, $t$ test, and simple linear regression were used to identify variables associated with development of BPD. To determine the contribution of the microorganisms to BPD after adjustment for other risk factors, logistic regression models were used. Variables found to be significantly associated with the development of BPD $(p<0.25)$ were used to build two logistic regression models with incidence of BPD at 36 wk PMA, and the combined outcome of BPD at 36 wk PMA or death due to lung disease, as the dependent variables. All initial variables of interest $(p<0.25)$ were entered and removed and reassessed using methods described by Hosmer and Lemeshow (39). Interaction terms were also explored based on clinical relevance.

Analysis was performed with SPSS 11.0 for Macintosh, and the SAS package, version 8.0, for Windows.

\section{RESULTS}

The cohort included 139 VLBW infants born from January 1, 1998, to December 31, 2002, and included 79\% (139/177) of eligible patients. Those not included were likely patients who were ventilated for less than $48 \mathrm{~h}$. Sample collection was not performed on weekends; therefore, patients born on weekends who were ventilated for short periods of time were not included. This group of patients should not differ systematically from included patients.

Demographic information regarding the cohort as well as data regarding neonatal outcomes can be found in Table 2 . Chorioamnionitis was defined by an obstetric clinical diagno-

Table 1. $P C R$ primers

\begin{tabular}{|c|c|c|c|c|c|}
\hline Organism & Name & Sequence & $\begin{array}{c}\text { Size of } \\
\text { PCR product }\end{array}$ & $\begin{array}{c}\text { Gene of } \\
\text { origin }\end{array}$ & Reference \\
\hline \multirow[t]{2}{*}{ Ureaplasma urealyticum } & U5 & 5'-CAATCTGCTCGTGAAGTATTAC-3' & $429 \mathrm{bp}$ & Urease & Blanchard et al. (38), 1993 \\
\hline & $\mathrm{U} 4$ & 5'-ACGACGTCCATAAGCAACT-3' & & & \\
\hline \multirow{2}{*}{ First step } & ADH1 & 5'-ACTACAAYATTGGCTACCAGG-3' & $440 \mathrm{bp}$ & Hexon & Couroucli et al. (14), 2000 \\
\hline & $\mathrm{ADH} 2$ & 5'-CAAAACATAAAGAAGKGTGGGC-3' & & & \\
\hline Second step & ADH11 & 5'-AACTTCCAGCCCATGAGCMG-3' & $330 \mathrm{bp}$ & & \\
\hline Chlamydia $s p$. & CHLAM02 & 5'-CGACTTCATCCYAGTCATCAG-3' & & & \\
\hline
\end{tabular}

$(\mathrm{Y}=\mathrm{C}+\mathrm{T}, \mathrm{K}=\mathrm{T}+\mathrm{G}, \mathrm{M}=\mathrm{A}+\mathrm{C}, \mathrm{B}=\mathrm{T}+\mathrm{C}+\mathrm{G}, \mathrm{H}=\mathrm{A}+\mathrm{T}+\mathrm{C}, \mathrm{R}=\mathrm{A}+\mathrm{G})$. 
Table 2. Study population $(n=139)$ demographics

\begin{tabular}{lc}
\hline \multicolumn{1}{c}{ Sex (male) } & $59 \%(83 / 139)$ \\
\hline Race & $58 \%(85 / 139)$ \\
White & $33 \%(44 / 139)$ \\
Hispanic & $4 \%(5 / 139)$ \\
African-American & $4 \%(5 / 139)$ \\
Asian/Pacific Islander & $26.8( \pm 1.9)$ \\
Mean EGA, wk & $941( \pm 257)$ \\
Mean birth weight, g & 14 \\
Deaths before 36 wk PMA & 8 \\
Deaths due to lung disease & 4 \\
Transfers before 36 wk PMA & $80 \%(108 / 135)$ \\
Prenatal steroids & $72 \%(97 / 135)$ \\
Prenatal antibiotics & $93 \%(129 / 139)$ \\
Surfactant & $66 \%(88 / 133)$ \\
PDA & $60( \pm 35)$ \\
Days of supplemental & \\
oxygen(median) & $14( \pm 18)$ \\
Days of mechanical & \\
ventilation(median) & $81( \pm 26)$ \\
Hospital days (median) & $22 \%(31 / 119)$ \\
ROP stage 3 or 4 & $14 \%(18 / 129)$ \\
IVH grade III or IV & $7 \%(10 / 139)$ \\
NEC & $37 \%(51 / 139)$ \\
Sepsis & $57 \%(69 / 121)$ \\
BPD at 36 wk PMA & $24 \%(34 / 139)$ \\
Ureaplasma detection & $16 \%(22 / 136)$ \\
Adenovirus detection & $6 \%(8 / 133)$ \\
Chlamydia sp. detection &
\end{tabular}

PDA, patent ductus arteriosus.

sis recorded in the mother's chart consisting of fever, elevated white blood cell count, and uterine tenderness ( Tables 3 and 5).

Twenty-four percent (34/139) of patients were positive for Ureaplasma sp. detection by PCR, and 16\% (22/136) were positive for adenovirus, consistent with published values $(14,17,33,40)$. Chlamydia sp. were rarely detected $(6 \%, 8 / 133)$ (Table 2). There were no racial differences in detection rates for any organism (Ureaplasma sp., $p=0.3$; adenovirus $p=$ 0.2 ; Chlamydia sp., $p=0.9$ ). There was no relationship between total white blood cell count at birth and detection status for any organism (Ureaplasma sp., $p=0.9$; adenovirus, $p=0.9$; Chlamydia sp., $p=0.6$ ). There was no relationship between total white blood cell count at birth and the outcome, $\mathrm{BPD}$, or death $(p=0.7)$.

At 36 wk PMA, 121 patients were still in the cohort. Of the remainder, 14 had died, and four had been transferred to other institutions. The proportions of transferred infants with Ureaplasma sp. (25\%) and adenovirus (25\%) detected were similar to those retained in the cohort.

At 36 wk PMA, 57\% of the population (69/121) met the criteria for BPD. Fifty-nine percent of the patients had either been diagnosed with BPD or had died from lung disease before 36 wk PMA (76/130). Incidence of death or BPD was similar in all racial groups.

BPD at 36 wk PMA. Several factors emerged as significant predictors of BPD at 36 wk PMA. Smaller and less gestationally mature infants were more likely to develop BPD, as were those who required longer courses of mechanical ventilation. The median number of days of ventilation was 24 in the BPD group versus 7 in the unaffected group. Each day of mechan-
Table 3. Bronchopulmonary dysplasia at 36 weeks PMA, univariate analyses

\begin{tabular}{|c|c|c|c|}
\hline & $\begin{array}{c}\text { BPD } 36 \\
\text { wk }(69 / 121)\end{array}$ & $\begin{array}{l}\text { No BPD } 36 \\
\text { wk }(52 / 121)\end{array}$ & $p$ \\
\hline Sex (male) & $57 \%(39 / 69)$ & $57 \%(30 / 52)$ & 1.0 \\
\hline \multicolumn{4}{|l|}{ Race } \\
\hline Caucasian & $58 \%(40 / 69)$ & $61 \%(32 / 52)$ & \\
\hline Hispanic & $33 \%(23 / 69)$ & $51 \%(18 / 52)$ & 0.61 \\
\hline African-American & $4 \%(3 / 69)$ & $2 \%(1 / 52)$ & \\
\hline Asian/Pacific Islander & $4 \%(3 / 69)$ & $4 \%(2 / 52)$ & \\
\hline Mean EGA, wk & $26.3( \pm 1.6)$ & $27.7( \pm 1.9)$ & $<0.001$ \\
\hline Mean birth weight, $g$ & $872( \pm 219)$ & $1070( \pm 227)$ & $<0.001$ \\
\hline Prenatal steroids & $82 \%(57 / 69)$ & $79 \%(38 / 52)$ & 0.60 \\
\hline Surfactant & $99 \%(68 / 69)$ & $85 \%(44 / 52)$ & 0.004 \\
\hline Chorioamnionitis & $14 \%(10 / 69)$ & $21 \%(11 / 52)$ & 0.47 \\
\hline PDA & $77 \%(52 / 69)$ & $53 \%(27 / 52)$ & 0.01 \\
\hline $\begin{array}{l}\text { Days of supplemental } \\
\text { oxygen(median) }\end{array}$ & $81( \pm 21)$ & $30( \pm 20)$ & $<0.001$ \\
\hline $\begin{array}{l}\text { Days of mechanical } \\
\text { ventilation(median) }\end{array}$ & $24( \pm 20)$ & $7( \pm 12)$ & $<0.001$ \\
\hline Hospital days (median) & $95( \pm 22)$ & $67( \pm 22)$ & $<0.001$ \\
\hline ROP stage 3 or 4 & $36 \%(25 / 69)$ & $8 \%(4 / 52)$ & $<0.001$ \\
\hline IVH grade III or IV & $16 \%(11 / 69)$ & $6 \%(3 / 52)$ & 0.43 \\
\hline Necrotizing enterocolitis & $7 \%(5 / 69)$ & $9 \%(5 / 52)$ & 0.74 \\
\hline Sepsis & $44 \%(30 / 69)$ & $27 \%(13 / 52)$ & 0.07 \\
\hline Ureaplasma sp. & $37 \%(26 / 69)$ & $8 \%(4 / 52)$ & $<0.001$ \\
\hline Adenovirus & $16 \%(11 / 69)$ & $12 \%(6 / 52)$ & 0.52 \\
\hline Chlamydia sp. & $9 \%(6 / 69)$ & $4 \%(2 / 52)$ & 0.33 \\
\hline
\end{tabular}

ical ventilation increased the risk of BPD by $8 \%$. These infants were also more likely to be treated for PDA. Sepsis was more prevalent; $44 \%$ of patients in the BPD group had at least one episode, in contrast to $27 \%$ of the unaffected group. BPDaffected infants also had significantly higher incidence of stage 3 or 4 ROP. Ureaplasma sp. detection was significantly associated with BPD at $36 \mathrm{wk}$, whereas adenovirus and Chlamydia sp. were not (Table 3).

The logistic model created for the 36 wk PMA outcome included EGA, PDA, sepsis, Ureaplasma sp. colonization, number of days of ventilation, and the interaction of days of ventilation and EGA. The interaction of days of ventilation with EGA was a significant predictor of BPD at 36 wk PMA. Days of ventilation were increasingly important as risk factors for BPD as babies became more gestationally mature. The OR for each additional ventilator day at 25 wk EGA was 1.05 , indicating that each day on the ventilator increased risk by $5 \%$. At 26 wk EGA, the additional risk was $8 \%$ per day, and at 28 wk EGA, it was $14 \%$ per day. The odds ratios (ORs) for these gestational ages are found in Table 4.

BPD at 36 wk PMA or death due to lung disease. Individual predictors of BPD or death due to lung disease were similar to those for BPD at 36 wk PMA (Table 5).

The model for the combined outcome of BPD at $36 \mathrm{wk}$ PMA or death from lung disease was identical to that for BPD at 36 wk PMA, although it was arrived at by an independent model-building process. Significant predictors of BPD included Ureaplasma sp. colonization and the interaction of ventilation with gestational age. The OR for Ureaplasma sp. colonization and BPD at 36 wk PMA or death due to lung disease was 4.2 (95\% CI: 1.03-17.0), indicating a fourfold 
Table 4. ORs for risk factors for BPD at 36 wk PMA

\begin{tabular}{lccc}
\hline \multicolumn{1}{c}{ Factor } & OR & $95 \%$ CI & $p$ \\
\hline PDA & 1.77 & $0.66-4.77$ & 0.26 \\
Sepsis & 0.65 & $0.23-1.88$ & 0.43 \\
Ureaplasma colonization & 2.85 & $0.8-10.0$ & 0.10 \\
$\quad \begin{array}{l}\text { EGA 25 wk, each day of } \\
\text { mechanical ventilation }\end{array}$ & 1.05 & $0.99-1.1$ & 0.053 \\
EGA 26 wk, each day of & 1.08 & $1.03-1.13$ & 0.003 \\
$\quad$ mechanical ventilation & & & \\
$\quad \begin{array}{l}\text { EGA 28 wk, each day of } \\
\text { mechanical ventilation }\end{array}$ & 1.14 & $1.06-.24$ & 0.0008 \\
\hline CI, confidence interval. & & &
\end{tabular}

Table 5. Bronchopulmonary dysplasia at 36 wk PMA or death due to lung disease, univariate analyses

\begin{tabular}{lccc}
\hline & Death or BPD at & No death or BPD at & \\
& 36 wk (76/130) & 36 wk $(54 / 130)$ & $p$ \\
\hline Sex (male) & $60 \%(45 / 76)$ & $56 \%(30 / 54)$ & 0.72 \\
Mean EGA, wk & $26.2( \pm 1.5)$ & $27.6( \pm 1.9)$ & $<0.001$ \\
Mean BW, g & $854( \pm 212)$ & $1055( \pm 240)$ & $<0.001$ \\
Prenatal steroids & $82 \%(60 / 74)$ & $73 \%(42 / 52)$ & 0.97 \\
Surfactant & $99 \%(74 / 75)$ & $85 \%(45 / 53)$ & 0.003 \\
Chorioamnionitis & $15 \%(11 / 76)$ & $19 \%(10 / 54)$ & 0.63 \\
PDA & $73 \%(54 / 74)$ & $53 \%(27 / 51)$ & 0.02 \\
Days of supplemental & $78( \pm 30)$ & $30( \pm 20)$ & $<0.001$ \\
$\quad$ & & \\
oxygen(median) & & $8( \pm 12)$ & $<0.001$ \\
$\quad$ vens of mechanical & $23( \pm 20)$ & & \\
Hospital days (median) & $95( \pm 22)$ & $67( \pm 22)$ & $<0.001$ \\
ROP stage 3 or 4 & $36 \%(27 / 76)$ & $8 \%(4 / 54)$ & $<0.001$ \\
Necrotizing enterocolitis & $7 \%(5 / 76)$ & $9 \%(5 / 54)$ & 0.74 \\
Sepsis & $41 \%(30 / 74)$ & $27 \%(13 / 48)$ & 0.13 \\
Ureaplasma sp. & $38 \%(29 / 76)$ & $6 \%(3 / 53)$ & $<0.001$ \\
Adenovirus & $17 \%(13 / 75)$ & $12 \%(6 / 51)$ & 0.39 \\
Chlamydia sp. & $8 \%(6 / 74)$ & $4 \%(2 / 50)$ & 0.36 \\
\hline
\end{tabular}

Table 6. ORs for risk factors for BPD at 36 wk PMA or death due to lung disease

\begin{tabular}{lccc}
\hline \multicolumn{1}{c}{ Factor } & OR & \multicolumn{1}{c}{$95 \%$ CI } & $p$ \\
\hline PDA & 1.59 & $0.6-4.22$ & 0.35 \\
Sepsis & 0.70 & $0.24-2.03$ & 0.51 \\
Ureaplasma colonization & 4.23 & $1.03-17.0$ & 0.04 \\
EGA 25 wk, each day of & 1.02 & $0.97-1.06$ & 0.42 \\
$\quad$ mechanical ventilation & & & \\
EGA 26 wk, each day of & 1.05 & $1.004-1.1$ & 0.03 \\
$\quad$ mechanical ventilation & & & \\
EGA 28 wk, each day of & 1.12 & $1.04-1.21$ & 0.003 \\
$\quad$ mechanical ventilation & & & \\
\hline
\end{tabular}

increase in risk of BPD or death in Ureaplasma sp.-colonized infants after statistical adjustment for the effects of PDA, sepsis, EGA, and days of ventilation. Ventilation became increasingly important as gestational age at birth increased. At 25 wk EGA, the risk increased $2 \%$ per day, $5 \%$ per day at 26 wk, and $12 \%$ per day at 28 wk (Table 6 ).

\section{DISCUSSION}

Endotracheal detection of Ureaplasma sp. emerged as an important predictor for the combined outcome of BPD or death due to lung disease in our population $(\mathrm{OR}=4.2)$ after statistical adjustment for the effects of gestational age, PDA, sepsis, and days of ventilation.

More than 20 candidate variables were investigated as potential confounders of the association between Ureaplasma sp. and BPD. Our study is the first to use PCR methods statistically corrected for duration of mechanical ventilation, an important risk factor for BPD. By using the most currently useful definition of BPD, a very sensitive detection method, and adjusting for several of the most significant risk factors for $\mathrm{BPD}$, this study improves on the previous literature.

The relationship between BPD and Ureaplasma sp. has been investigated for $>20 \mathrm{y}$. Most publications in the presurfactant era clearly demonstrated an association; a metaanalysis of 18 publications between 1988 and 1994 demonstrated an increased risk of BPD in colonized infants (OR = 1.72) (41).

Since surfactant has come into common usage, the data conflict. Studies in infants with mean birth weights of 827 $1000 \mathrm{~g}$ demonstrated OR of 2.0-3.8 (24,26-28), yet in studies of larger infants (975-1300 g) there was no association detected between Ureaplasma sp. and BPD $(14,33,35)$. This ambiguity may be related to the difference in size, as smaller, more gestationally immature infants are at higher risk of BPD. A population with a lower prevalence of BPD would require a larger sample size to detect any effect of the organism. Our population had a high prevalence BPD, increasing our ability to detect differences in BPD between colonized and uncolonized infants.

A recent meta-analysis determined that Ureaplasma sp. colonization is associated with BPD at 36 wk PMA (OR = $1.62,95 \%$ CI: 1.1-2.3) (42). Our study differs from many of the studies in the analysis due to use of PCR and adjustment for known confounders.

Another potential explanation for the controversy may be the modality used to detect Ureaplasma sp. Relying on a single clinical culture may misclassify up to $40 \%$ of positive patients as negative $(13,17,37,43)$. PCR is more sensitive than culture and can detect both low numbers of organisms and dead organisms $(36,37,44)$. Sensitivities for PCR detection of Ureaplasma range from $90 \%$ to $100 \%$ in neonatal endotracheal aspirate samples. Contemporaneous cultures of the same specimens yield detection sensitivities of 40\%-91\% (36,37). Although PCR detection does not differentiate between colonization and infection, this will only underestimate any association, as infected infants are presumably at greater risk of complications. Unfortunately, it is impossible to clearly determine which patients are incidentally colonized with these organisms and which have true pathologic infection, regardless of detection method.

We also investigated the contributions of adenovirus and Chlamydia sp. detection to BPD. Adenovirus was first reported in association with BPD by Couroucli et al. (14) in a population with EGA $<30$ wk by PCR . They found no association between Ureaplasma sp. and BPD. The majority of adenovirus isolates were type 5 , a group $\mathrm{C}$ adenovirus that has been detected in neonatal myocarditis and pediatric respiratory infection. No clinical data such as gestational age, birth weight, and neonatal diagnoses were reported. 
Prosch et al. (40) screened VLBW infants for adenovirus by both PCR and culture techniques. Their cohort was similar to ours in terms of clinical and demographic parameters. They detected adenovirus at a similar rate to that of Couroucli et al. (14), but did not demonstrate an association between adenovirus and BPD. The adenovirus isolates detected by Prosch $e t$ al. were predominantly type 2 , another group $\mathrm{C}$ adenovirus that is associated with respiratory disease.

We detected adenovirus at a rate similar to both groups $(14,40)$ and also demonstrated no association with BPD. Our isolates were not sequenced. Our sample size and prevalence of adenovirus were similar to those of Couroucli et al. and was adequate to have reproduced this finding. That we did not suggests that their population is different in some important way from the very immature, high-risk population we studied or that their association was due to chance. The role of adenovirus in BPD is still uncertain. Chlamydia sp. were uncommon in our population (eight patients) and not associated with BPD.

Like all epidemiologic studies, ours contained potential limitations. Our study was limited to intubated VLBW infants. We obtained samples on $79 \%$ of eligible infants. The excluded patients were likely intubated for shorter durations; however, no data were collected to support this assertion. If intubated for a shorter duration, they would represent a group at lower risk of BPD, and if included, might lead to a shift in the OR of our logistic models toward 1. Our population consisted of a subset of the total who were smaller, younger, and, in general, at higher risk of BPD. This is a potential source of selection bias. Our findings can only be generalized to intubated VLBW infants.

Infants who never require mechanical ventilation can still develop BPD. With mechanical ventilation being used more sparingly, other risk factors for BPD become more important to understand. Given the sample size and the large effect of mechanical ventilation on the risk of BPD in our population, there was no way to adequately assess the effects of other risk factors, such as sepsis, PDA, and maternal chorioamnionitis. Therefore, our study cannot be generalized to the entire VLBW population, only those who have been mechanically ventilated.

We clearly demonstrated that after accounting for other common risk factors for $\mathrm{BPD}$, the presence of Ureaplasma predisposed intubated VLBW infants to BPD or death due to lung disease. Ureaplasma is an independent risk factor for BPD in this population. The mechanism for this increased risk is not known, but could be due to inflammation arising before birth due to intrauterine exposure. Indeed, our sample collection in the first $72 \mathrm{~h}$ of life reflects such antenatal or perinatal exposure to Ureaplasma. We did not have amniotic fluid samples or other maternal data with which to determine timing or chronicity of Ureaplasma exposure. We collected total white blood cell counts at birth for all subjects and found no association between elevated white blood cell count and Ureaplasma colonization. White blood cell counts are a crude estimate of systemic inflammation, and we did not collect other data such as pulmonary cytokine levels to assess the level of pulmonary inflammation, as others have done $(11,12)$.
Future studies should be aimed at combining epidemiologic studies with contemporaneous measurement of inflammatory cytokines to determine whether Ureaplasma sp. is causing an inflammatory response in neonates who are then followed for the development of BPD. Species and serovar ascertainment would also be helpful in such studies to identify any varying pathogenicity of the Ureaplasma sp. Finally, no large prospective studies of antibiotic treatment of Ureaplasma sp., starting in the first days of life, exist. Such a trial could contribute much to the understanding of the impact of this microbe in this vulnerable population. Understanding the pathogenesis of BPD is essential to the development of interventions to optimize the health and long-term well-being of our tiniest patients.

Acknowledgments. The authors thank Susan Escoe, Jiaqing Pang, Meena Mishra, Ian McMillan, Elaine Walker, and Spencer Watson for assistance in data collection and sample processing. They are grateful to unpublished contributions by Drs. Donald Buffkin, Vincent Koletar, and Theresa Kuforiji in identifying the importance of Ureaplasma in BPD in Oregon.

\section{REFERENCES}

1. Bancalari E, Claure N, Sosenko IR 2003 Bronchopulmonary dysplasia: changes in pathogenesis, epidemiology and definition. Semin Neonatol 8:63-71

2. Jobe AH, Bancalari E 2001 Bronchopulmonary dysplasia. Am J Respir Crit Care Med 163:1723-1729

3. Northway WH Jr, Rosan RC, Porter DY 1967 Pulmonary disease following respirator therapy of hyaline-membrane disease. Bronchopulmonary dysplasia. N Engl J Med 276:357-368

4. Charafeddine L, D'Angio CT, Phelps DL 1999 Atypical chronic lung disease patterns in neonates. Pediatrics 103:759-765

5. Bancalari E, Gonzalez A 2000 Clinical course and lung function abnormalities during development of neonatal chronic lung disease. In: Bland RD, Coalson, JJ (eds) Chronic Lung Disease in Early Infancy. Marcel Dekker, New York, pp 41-64

6. Ohlsson A, Wang E, Vearncombe M 1993 Leukocyte counts and colonization with Ureaplasma urealyticum in preterm neonates. Clin Infect Dis 17:S144-S147

7. Panero A, Pacifico L, Rossi N, Roggini M, Chiesa C 1995 Ureaplasma urealyticum as a cause of pneumonia in preterm infants: analysis of the white cell response. Arch Dis Child Fetal Neonatal Ed 73:F37-F40

8. Groneck P, Goetze-Speer B, Speer CP 1996 Inflammatory bronchopulmonary response of preterm infants with microbial colonisation of the airways at birth. Arch Dis Child Fetal Neonatal Ed 74:F51-F55

9. Patterson AM, Taciak V, Lovchik J, Fox RE, Campbell AB, Viscardi RM 1998 Ureaplasma urealyticum respiratory tract colonization is associated with an increase in interleukin 1-beta and tumor necrosis factor alpha relative to interleukin 6 in tracheal aspirates of preterm infants. Pediatr Infect Dis J 17:321-328

10. Lyon A 2000 Chronic lung disease of prematurity. The role of intra-uterine infection. Eur J Pediatr 159:798-802

11. De Dooy JJ, Mahieu LM, Van Bever HP 2001 The role of inflammation in the development of chronic lung disease in neonates. Eur J Pediatr 160:457-463

12. Groneck P, Schmale J, Soditt V, Stutzer H, Gotze-Speer B, Speer CP 2001 Bronchoalveolar inflammation following airway infection in preterm infants with chronic lung disease. Pediatr Pulmonol 31:331-338

13. Colaizy TT, Kuforiji T, Sklar RS, Pillers DA 2003 PCR methods in clinical investigations of human ureaplasmas: a minireview. Mol Genet Metab 80:389-397

14. Couroucli XI, Welty SE, Ramsay PL, Wearden ME, Fuentes-Garcia FJ, Ni J, Jacobs TN, Towbin JA, Bowles NE 2000 Detection of microorganisms in the tracheal aspirates of preterm infants by polymerase chain reaction: association of adenovirus infection with bronchopulmonary dysplasia. Pediatr Res 47:225-232

15. Numazaki K, Chiba S, Kogawa K, Umetsu M, Motoya H, Nakao T 1986 Chronic respiratory disease in premature infants caused by Chlamydia trachomatis. J Clin Pathol 39:84-88

16. Garland SM, Bowman ED 1996 Role of Ureaplasma urealyticum and Chlamydia trachomatis in lung disease in low birth weight infants. Pathology 28:266-269

17. Da Silva O, Gregson D, Hammerberg O 1997 Role of Ureaplasma urealyticum and Chlamydia trachomatis in development of bronchopulmonary dysplasia in very low birth weight infants. Pediatr Infect Dis J 16:364-369

18. Abele-Horn M, Peters J, Genzel-Boroviczeny O, Wolff C, Zimmermann A, Gottschling W 1997 Vaginal Ureaplasma urealyticum colonization: influence on pregnancy outcome and neonatal morbidity. Infection 25:286-291

19. Sanchez PJ, Regan JA 1990 Vertical transmission of Ureaplasma urealyticum from mothers to preterm infants. Pediatr Infect Dis J 9:398-401 
20. Cassell GH, Waites KB, Crouse DT, Rudd PT, Canupp KC, Stagno S, Cutter GR 1988 Association of Ureaplasma urealyticum infection of the lower respiratory tract with chronic lung disease and death in very-low-birth-weight infants. Lancet 2:240-245

21. Horowitz S, Landau D, Shinwell ES, Zmora E, Dagan R 1992 Respiratory tract colonization with Ureaplasma urealyticum and bronchopulmonary dysplasia in neonates in southern Israel. Pediatr Infect Dis J 11:847-851

22. Payne NR, Steinberg SS, Ackerman P, Chrenka BA, Sane SM, Anderson KT, Fangman JJ 1993 New prospective studies of the association of Ureaplasma urealyticum colonization and chronic lung disease. Clin Infect Dis 17:S117-S121

23. Wang EE, Cassell GH, Sanchez PJ, Regan JA, Payne NR, Liu PP 1993 Ureaplasma urealyticum and chronic lung disease of prematurity: critical appraisal of the literature on causation. Clin Infect Dis 17:S112-S116

24. Iles R, Lyon A, Ross P, McIntosh N 1996 Infection with Ureaplasma urealyticum and Mycoplasma hominis and the development of chronic lung disease in preterm infants. Acta Paediatr 85:482-484

25. Pacifico L, Panero A, Roggini M, Rossi N, Bucci G, Chiesa C 1997 Ureaplasma urealyticum and pulmonary outcome in a neonatal intensive care population. Pediatr Infect Dis J 16:579-586

26. Abele-Horn M, Genzel-Boroviczeny O, Uhlig T, Zimmermann A, Peters J, Scholz M 1998 Ureaplasma urealyticum colonization and bronchopulmonary dysplasia: a comparative prospective multicentre study. Eur J Pediatr 157:1004-1011

27. Hannaford K, Todd DA, Jeffery H, John E, Blyth K, Gilbert GL 1999 Role of Ureaplasma urealyticum in lung disease of prematurity. Arch Dis Child Fetal Neonatal Ed 81:F162-F167

28. Perzigian RW, Adams JT, Weiner GM, Dipietro MA, Blythe LK, Pierson CL, Faix RG 1998 Ureaplasma urealyticum and chronic lung disease in very low birth weight infants during the exogenous surfactant era. Pediatr Infect Dis J 17:620-625

29. Smyth AR, Shaw NJ, Pratt BC, Weindling AM 1993 Ureaplasma urealyticum and chronic lung disease. Eur J Pediatr 152:931-932

30. Saxen H, Hakkarainen K, Pohjavuori M, Miettinen A 1993 Chronic lung disease of preterm infants in Finland is not associated with Ureaplasma urealyticum colonization. Acta Paediatr 82:198-201

31. Jonsson B, Karell AC, Ringertz S, Rylander M, Faxelius G 1994 Neonatal Ureaplasma urealyticum colonization and chronic lung disease. Acta Paediatr 83:927-930

32. Heggie AD, Jacobs MR, Butler VT, Baley JE, Boxerbaum B 1994 Frequency and significance of isolation of Ureaplasma urealyticum and Mycoplasma hominis from cerebrospinal fluid and tracheal aspirate specimens from low birth weight infants. J Pediatr 124:956-961
33. Heggie AD, Bar-Shain D, Boxerbaum B, Fanaroff AA, O'Riordan MA, Robertson JA 2001 Identification and quantification of ureaplasmas colonizing the respiratory tract and assessment of their role in the development of chronic lung disease in preterm infants. Pediatr Infect Dis J 20:854-859

34. van Waarde WM, Brus F, Okken A, Kimpen JL 1997 Ureaplasma urealyticum colonization, prematurity and bronchopulmonary dysplasia. Eur Respir J 10:886890

35. Ollikainen J, Korppi M, Heiskanen-Kosma T, Heinonen K 2001 Chronic lung disease of the newborn is not associated with Ureaplasma urealyticum. Pediat Pulmonol 32:303-307

36. Cunliffe NA, Fergusson S, Davidson F, Lyon A, Ross PW 1996 Comparison of culture with the polymerase chain reaction for detection of Ureaplasma urealyticum in endotracheal aspirates of preterm infants. J Med Microbiol 45:27-30

37. Abele-Horn M, Wolff C, Dressel P, Zimmermann A, Vahlensieck W, Pfaff F, Ruckdeschel G 1996 Polymerase chain reaction versus culture for detection of Ureaplasma urealyticum and Mycoplasma hominis in the urogenital tract of adults and the respiratory tract of newborns. Eur J Clin Microbiol Infect Dis 15:595-598

38. Blanchard A, Hentschel J, Duffy L, Baldus K, Cassell GH 1993 Detection of Ureaplasma urealyticum by polymerase chain reaction in the urogenital tract of adults, in amniotic fluid, and in the respiratory tract of newborns. Clin Infect Dis 17:S148-S153

39. Hosmer DW Jr, Lemeshow S 2000 Applied Logistic Regression. John Wiley \& Sons, New York

40. Prosch S, Lienicke U, Priemer C, Flunker G, Seidel WF, Kruger DH, Wauer RR 2002 Human adenovirus and human cytomegalovirus infections in preterm newborns: no association with bronchopulmonary dysplasia. Pediatr Res 52:219_ 224

41. Wang EE, Ohlsson A, Kellner JD 1995 Association of Ureaplasma urealyticum colonization with chronic lung disease of prematurity: results of a metaanalysis. J Pediatr 127:640-644

42. Schelonka RL, Katz B, Waites KB, Benjamin DK Jr 2005 Critical appraisal of the role of Ureaplasma in the development of bronchopulmonary dysplasia with metaanalytic techniques. Pediatr Infect Dis J 24:1033-1039.

43. Nelson S, Matlow A, Johnson G, Th'ng C, Dunn M, Quinn P 1998 Detection of Ureaplasma urealyticum in endotracheal tube aspirates from neonates by PCR. J Clin Microbiol 36:1236-1239

44. Teng K, Li M, Yu W, Li H, Shen D, Liu D 1994 Comparison of PCR with culture for detection of Ureaplasma urealyticum in clinical samples from patients with urogenital infections. J Clin Microbiol 32:2232-2234 